\title{
Toward knowledge structuring of sustainability science based on ontology engineering
}

\author{
Terukazu Kumazawa • Osamu Saito · \\ Kouji Kozaki · Takanori Matsui · Riichiro Mizoguchi
}

Published online: 12 June 2009

(C) Integrated Research System for Sustainability Science, United Nations University, and Springer 2009

\section{Erratum to: Sustain Sci (2009) 4:99-116 \\ DOI 10.1007/s11625-008-0063-z}

The following sentence was inadvertently omitted from the Acknowledgments:

This work was also supported by the Global Environment Research Fund (Hc-082) of the Ministry of the Environment, Japan.

The online version of the original article can be found under doi:10.1007/s11625-008-0063-z.

\section{T. Kumazawa $(\square)$}

Research Institute for Sustainability Science (RISS),

Center for Advanced Science and Innovation,

Advanced Research Building 6F, Osaka University,

2-1 Yamada-oka, Suita, Osaka 565-0871, Japan

e-mail: kumazawa@riss.osaka-u.ac.jp

O. Saito

Waseda Institute for Advanced Study, Waseda University,

Bldg. 51-10F-10, 3-4-1 Okubo, Shinjuku,

Tokyo 169-8555, Japan

e-mail: o.saito@aoni.waseda.jp

K. Kozaki · R. Mizoguchi

The Institute of Scientific and Industrial Research (ISIR),

Osaka University, 8-1 Mihogaoka, Ibaraki,

Osaka 567-0047, Japan

e-mail: miz@ei.sanken.osaka-u.ac.jp

\section{T. Matsui}

Division of Sustainable Energy and Environmental Engineering,

Graduate School of Engineering, Osaka University,

Environmental Engineering Building (S4), 2-1, Yamadaoka,

Suita, Osaka 565-0871, Japan

e-mail: matsui@see.eng.osaka-u.ac.jp
The corrected Acknowledgments should read:

This research was supported by MEXT through Special Coordination Funds for Promoting Science and Technology, as a part of the IR3S flagship research project "Development of an Asian Resource Circulating Society" undertaken by Osaka University and Hokkaido University. This work was also supported by the Global Environment Research Fund (Hc-082) of the Ministry of the Environment, Japan. This study was made possible through a series of workshops on SS knowledge structuring coordinated by the Osaka University Research Institute for Sustainability Science (RISS). We would like to extend our sincere appreciation to Associate Professor Steven Kraines (University of Tokyo) for his invaluable comments and advice. We would like to thank Assistant Professor Michinori Uwasu (RISS) for organizing these workshops and Mr. Mamoru Ohta (Enegate Co., Ltd.) for supporting the development of Hozo and collecting the relevant information for the SS ontology. We gratefully acknowledge helpful discussions with Professor Hideaki Takeda and Associate Professor Masaru Yarime on several points of SS knowledge structuring. 